\title{
The importance of Ergonomics for Dental Medicine Procedures in the Triad Position: The Patient, the Dentist, and the Surgical Microscope
}

\author{
L.Miguel Carreira ${ }^{1,2,3,5}$; P.Azevedo ${ }^{3}$; J. Dias ${ }^{4,5}$ \\ ${ }^{1-}$ Faculty of Veterinary Medicine, University of Lisbon (FMV/ULisboa)-Portugal \\ 2 - Centre for Interdisciplinary Research Animal Health (CIISA) - FMV/ULisboa - Portugal \\ 3 - Anjos of Assis Veterinary Medicine Centre (CMVAA), Barreiro - Portugal \\ 4 - Egas Moniz Health Sciences Institute - Caparica- Portugal \\ 5 - Human Dental Clinical, Lisboa - Portugal
}

\begin{abstract}
Ergonomics is an autonomous science that studies the interaction of the human body with the working environment constituent factors where it is integrated. Its perspective is from the final analysis the elaboration of guidelines, with the objective of eliminating anti-anatomical postures and non-productive movements at work, preventing or extending the physical and mental fatigue limits of the worker, and preventing the onset of signs and symptoms of diseases, thus contributing to better professional performance. In dentistry, as in other fields of medicine, initially work with the surgical microscope presents as main difficulty the ergonomics issue. About $77 \%$ of the dentists that use surgical microscope pointed out that when started using microsurgical techniques, achieving good ergonomics of the triad position for dental procedures, which results from the obtainment of the dentist correct body position relative to the microscope, to the patient, and to the operative field at the same time, was the main difficulty. A work performed by a team accustomed to use the surgical microscope is quickly and safely performed, without excessive and unnecessary physical wear, promoting in the patient a sense of security in relation to the professionals and achieving excellent results.
\end{abstract}

Keywords: Ergonomics; Dentistry; Dentist; Patient; Surgical Microscope

\section{INTRODUCTION}

Empirically, man has always sought ways to adapt the environment to his needs, such as creating and adapting different instruments to his anatomical characteristics. Ergonomics as an autonomous science appeared during the Second World War period. The word ergonomics results from combining the words ergos (work) and nomos (law), and it is the science that studies the interaction of the human body with the working environment constituent factors where it is integrated. [1] Currently the concept of ergonomics is defined as "the science that aims to fit the human being with his work environment in a comfortable and productive way, adapting the working conditions to man's anatomical and physiological characteristics." [2] It is concerned with the body biomechanics, trying to understand in detail all the movements performed by the professional, and how its poor development may affect the body. Its perspective is from the final analysis the elaboration of guidelines, with the objective of eliminating anti-anatomical postures and non-productive movements at work, preventing or extending the physical and mental fatigue limits of the worker, and preventing the onset of signs and symptoms of diseases, thus contributing to better professional performance. [38] In dentistry, as in other fields of medicine, initially work with the surgical microscope presents as main difficulty the ergonomics issue. About $77 \%$ of the dentists that use surgical microscope pointed out that when started using microsurgical techniques, achieving good ergonomics of the triad position for dental procedures, which results from the obtainment of the dentist correct body position relative to the microscope, to the patient, and to the operative field at the same time was the main difficulty. [9-27] The other two major problems referred by those dentists were: 1) the fine or meticulous manipulation and 2) the structure details perception. Aiming to solve or minimize these problems, and 


\section{L.Miguel Carreira et al.}

to understand more about the dentist's limitations and capabilities when working under magnification systems, six main areas of research in surgical microscope ergonomics have been developed, namely, 1) the visual perception, 2) the tremor control and fine or meticulous manipulation development, 3 ) the biomechanics' motions of the hand and the arm, 4) the skills acquisition process, 5) the neutral body posture and 6) the microsurgery instruments design. [28] Visual perception is assumed to be a pillar of microsurgery technique since the visual function overlaps to the kinetic function. All the work will be developed in a very small surgical field where tactile sense becomes less useful for the control of procedures to be undertaken. At the beginning the movements performed under the magnification system are much slower than those without it due to the necessity to acquired newly skills. $[24,43,44]$ The tremor control is fundamental for a good microsurgery technique. Tremor is physiological in all subjects, being a phenomenon processed at the spinal cord level and directly related to the development of so-called fine or meticulous manipulation. [25,29-37] According to Voigt (1963) [25], the physiological tremor is characterized by a 0.5 to $3.0 \mathrm{~mm}$ amplitude and by a 7 to 30 vibrations/second frequency. However, it may be modified by various factors which may or may not be controlled by the dentist. Three types of tremor can be considered, namely, 1) short-term (influenced by the direction of the motion to be developed, which may be more or less stabilized in accordance with the technology that support its development), 2) median-term (which can be influenced by several parameters such as the training level, the individual experience, or even the consumption of substances like caffeine, nicotine, or alcohol), and 3) long-term (which results from factors that cannot be reversed by the dentist, such as the age and health status). [38-41] The biomechanics' motions of the hand and the arm has been widely studied, since it relates to the ability to develop with precision, complex motions types during microsurgery, learning and improving techniques of how to handle the skills acquisition capacity. Skills acquisition was defined by Glencross in 1977 as the ability in learning making patterns of highly advanced movements in order to achieve excellent results. The skills acquisition process is divided the into three phases or stages: 1) coding, 2) temporal organization and 3) hierarchical organization. [42,43] Coding, is the phase in which the individual will learn to associate a certain movement with a specific result. The temporal organization, is an intermediate stage in the skills acquisition process, and is the ability of the individual to relate the encoded movements seized during the first phase to a rhythmic sequence allowing for errors correction in real time. Finally, the hierarchical organization stage, results from a sequence's combination of rhythmic movements developed in accordance with a comprehensive global strategy of work. Prolonged work under high magnification systems like surgical microscope, requires by the dentist the develop of a good body posture, which should be neutral. The dentist should be positioned with the vertebral column straight; the seat height should be adjusted to allow the elbow joint to stay at the working area level, the arms must stay along the trunk, and the forearms and hands must be fully supported in order to decrease the tremors. [43,44]

\section{The Triad Position for Dental Medicine Procedures: The Patient, the Surgical Microscope, AND THE DENTIST}

In 1980, Marquart stated that working, whether standing or sitting, is not synonymous with working in a rational or ergonomic manner. According to Harbor (1991) [25], faster body movements on a smaller scale should be preferred, and unnecessary movements should be eliminated or delegated to another person. In 1994, Saquy and Pécora [25] concluded that the ideal posture to work with the surgical microscope was with an average slope of the spine in the anteroposterior direction, in order to wear the supporting muscles less. In 1997, Rubinstein and Kim [57] stated that the ideal working position is one that results from a position combination of the patient, the microscope and the dentist. Achieving a balance between the patient's head, the chair, the microscope, the hardware accessories, the lights, and the dentist will achieve what is known as the optimum or correct working position for the triad, which always may present some variations according to the type of procedures to be done. Avoiding vicious body postures that require relevant static work or forces (particularly of the shoulder and back), and promote in the dentist the idea that carrying out the tasks preferably in the sitting position and as close as possible to the body is always desirable. [8,12,15,17,20,22,26,45,46]

\subsection{The Patient}

The patient should be positioned varying from a slight supine to a Trendelenburg position, so that the working region being as close as possible to the surgical microscope. The head should be supported at the centre of the headboard in order to ensure greater comfort and less strain on the neck muscles 
(using head positioners or even pads that change the head angle position assumed in the chair), and allowing the dentist to conduct the patient's head movements. In addition, the patient's head position can be further adjusted by using the horizontal and vertical control buttons of the chair, allowing to control the relative distance to the microscope. To perform procedures in the maxilla and in the mandible the most suitable positions for the head placement are those usually adopted in daily work; i.e., the occlusal plane perpendicular to the ground for the maxilla procedures, and the occlusal plane parallel to the ground for the mandible procedures. [45-48]

\subsection{The Surgical Microscope}

The surgical microscope should be positioned in the room enabling the dentist to use it with just one hand, quickly and with a single manoeuvre, in order to get it in line with a perpendicular axis to the tissues where the dentist will work. A good guidance for this is to establish an imaginary line in which the dentist gets a direct view of the surgical field, then positioning the surgical microscope along this same imaginary line. In addition, it is possible to select lower slopes of $20^{\circ}$ in the optics, which allow an increase of the surgical field image. [45-48] To work with the surgical microscope in the maxilla with indirect vision, the patient should be slightly inclined with the chin up, and the light microscope should be focused on the dental mirror in order to be reflected onto surgical surfaces. To work in the anterior teeth block of the maxilla, is it recommended that the microscope head be slightly tilted away from the vertical axis, angling up toward the crown to the apex of the teeth. This angle will alleviate the overlapping effect of the instrumentation in use, allowing the tips of these to be fully under direct vision and control. The retraction of soft tissue in the posterior region is hampered by the presence of the zygoma. [23,28,45-48,50,55] When the work is developed in the anterior block of the mandible, the teeth that comprise it are easily seen with direct vision if the dentist takes a position of 12 hours in a frame clock in relation to the patient. Indirect vision with a mirror provides an accurate lingual or vestibular orientation. The light microscope should be represented by a perpendicular line to the vestibular teeth surfaces. In this arcade, the position that offers the greatest difficulty in surgical microscope work is the molar occlusal view. Also, some peculiarities of the region require some considerations, namely: 1) the parallel positioning of the cortical bone relative to the ground may not be possible to achieve, because it requires in many cases that the patient recline the head to an uncomfortable angle, 2) certain desirable angles can be compromised by the limitations of the reflection phenomenon and also by the required angle to the patient head, and 3) the posterior soft tissues retracting is hampered by the presence of the external oblique ridge. $[23,28,45-48,55,56]$

\subsection{The Dentist}

The ergonomic dentist associated with the use of the surgical microscope is to determine whether the work will be performed with direct or indirect vision of the surgical field, which implies changes in the surgical microscope position, if there is a need to focus the image directly or with the aid of mirrors. Preferably the work should be developed with direct vision, allowing the light to be perpendicular to the plane, contrary to what happens when the dentist works with indirect vision, where the light must be perpendicular to the mirror plane. The dentist should always assume a location behind the patient's head, with an orientation between 9 and 12 o'clock frame, sitting on a bench or adjustable chair, with his head slightly tilted, back straight, parallel shoulders, arms and elbows close to the body, passively bent in a neutral angle of $90^{\circ}$, thighs parallel to the ground, and feet apart and fully supported on the ground so that the large muscle groups remain in equilibrium and at rest. [49,50] Recourse to a sitting posture is indicated for tasks requiring precision, lower energy costs, and to avoid unnecessary movements. The dentist's chair must have at least five wheels, allowing it to form an angle between $105^{\circ}$ and $110^{\circ}$ between the dentist's leg and thigh when seated, ensuring that it pelvis is tilted forward. This is important since the higher the achieved angle, the greater the compression of the return venous circulation. The chair seat's dimensions should allow the dentist to sit without pressure on any region of the pelvis and thighs. The seat must be divided into two parts to assure a balanced position, presenting a horizontal portion with a $15 \mathrm{~cm}$ minimum length (the maximum distance between the ischial tuberosities and the back of the body) and a front anticlinal angle of $20^{\circ}$ in relation to the horizontal plane, which is considered optimal to support equal thighs. A slight inclination up to $6^{\circ}$ to $8^{\circ}$ in an oblique position can be used to promote an active position with a required degree of lordosis. A steeper slope will result in a tendency for the dentist to 


\section{L.Miguel Carreira et al.}

slide forward. The maximum seat depth should be $40 \mathrm{~cm}$, the width $40 \mathrm{~cm}$ to $43 \mathrm{~cm}$, and the height of the lumbar support $12 \mathrm{~cm}$ to $30 \mathrm{~cm}$ in length, to not exceed the iliac crest level. The lumbar support can be vertically adjustable between $17 \mathrm{~cm}$ and $22 \mathrm{~cm}$, and up to $24 \mathrm{~cm}$ for very tall dentists. Otherwise, it will inhibit free arm movements. The maximum seat height may vary between $47 \mathrm{~cm}$ and $63 \mathrm{~cm}$ from the ground (Figure 1). ${ }^{51-53}$ All the chair or bench margins should be rounded. Some chairs have incorporated arms favouring the dentist's forearms and elbows, ensuring that the hands do not deviate from the nuclear-centric position, since it is that which will provide greater dexterity and better control in micro-movements, while limiting fatigue and strain. The vertical position taken by the dentist allows him to get space for his legs under the patient chair, and the fact that it can be raised or lowered helps the dentist to keep a stable neutral body posture. Correct ocular selection is also critical, as it will affect the correct position of the surgical microscope. They will enable the dentist to have an optimal view of the tooth, even though in some cases it is necessary to use indirect vision. The dentist should not divert his eyes from the oculars, in order to avoid needing to redevelop the visual accommodation process. Similarly, he should not withdraw his hands from the surgical field to access instruments and consumables; these must be placed in his hands by the dental assistant in the position that will be used. [45-48,54,57]

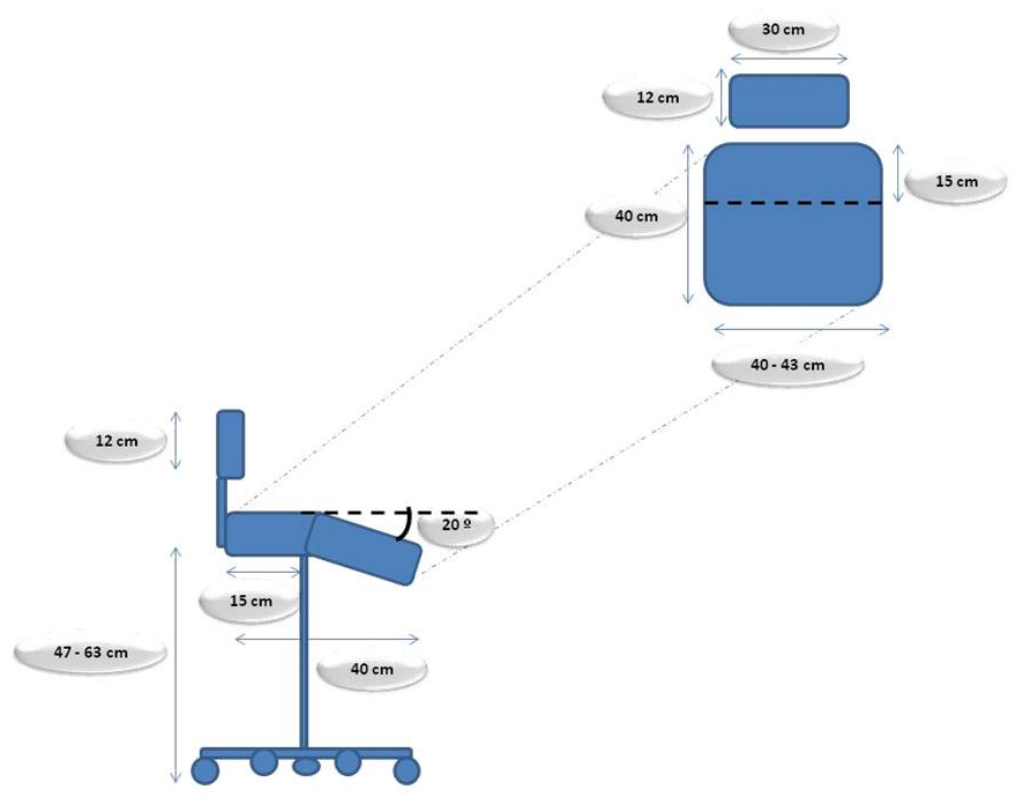

Figure 1. Representation of the dentist work ideal chair covering the measures and angles required to ensure good ergonomics during all procedures performed, allowing less fatigue and getting better performance by the professional.

\section{CONClusion}

The surgical microscope work requires from the dentist a long learning curve. The work should be developed slowly in order to avoid undue trauma to the regional tissues, preserving to the maximum the native tissues and reducing the risk of iatrogenic injuries. The ideal working posture results from a combination of the patient, the surgical microscope and the dentist position, achieving what is known as the working position for the triad. A work performed by a dentist familiarized with the use of the surgical microscope is quickly and safely performed, without excessive and unnecessary physical wear, promoting in the patient a sense of security in relation to the professionals and achieving excellent results in the dental procedures.

\section{ACKNOWLEDGMENTS}

The author thanks CIISA - Centre for Interdisciplinary Research in Animal Health, of Faculty of Veterinary Medicine, University of Lisbon (FMV-ULisboa), Portugal; and Anjos of Assis Veterinary Medicine Centre (CMVAA), Barreiro, Portugal.

The author wishes to thanks to the Editor of the ARC Journal of Dental Sciences for his support allowing having this ARC-Free article submission. 
The importance of Ergonomics for Dental Medicine Procedures in the Triad Position: The Patient, the Dentist, and the Surgical Microscope

\section{Conflict of interest statement}

The author declare that they have no conflict of interest. This research received no specific grant from any funding agency in the public, commercial, or not-for-profit sectors.

\section{REFERENCES}

[1] Grandjean E. (1998). Manual de ergonomia: adaptando o trabalho ao homem. Porto Alegre: Bookman, Brazil

[2] International Ergonomics Association - What is Ergonomics; IEA, 2016. Accessed at: http://www.iea.cc/whats/index.html

[3] Meister, D. (1999). The History of Human Factors and Ergonomics. Mahwah, N.J.: Lawrence Erlbaum Associates. ISBN 0-8058-2769-2.

[4] Jeffress, CN. (2000). BEACON- Biodynamics and Ergonomics Symposium. University of Connecticut, Farmington, Conn

[5] Stanton, N.; Salmon, P., Walker G., Baber, C., Jenkins, D. (2005). Human Factors Methods; A Practical Guide For Engineering and Design. Aldershot, Hampshire: Ashgate Publishing Limited.

[6] Brookhuis, K., Hedge, A., Hendrick, H., Salas, E., and Stanton, N. (2005). Handbook of Human Factors and Ergonomics Models. Florida: CRC Press.

[7] Walsh IA; Oishi J; Coury H. (2008). Clinical and functional aspects of work-related musculoskeletal disorders among active workers. Programa de Pós-graduação em Fisioterapia. Universidade Federal de São Carlos. São Carlos, SP, Brasil. Rev. Saúde Pública, vol.42;1;São Paulo

[8] Hokwerda O. (2008). Vision of the future of ergonomics in dentistry. Ned Tijdschr Tandheelkd.;115(8):429-434.

[9] Dougherty M.(2001). Ergonomic principles in the dental setting: Part 1. Dental Products Reports. Accessed: www.dentalproducts.net

[10] Graham C.(2002b). Ergonomics in Dentistry, Part 2. Accessed at: http://www.dentistrytoday.com/ergonomics/1111

[11] Thornton LJ, Stuart-Buttle C, Wyszynski TC, Wilson ER. (2004). Physical and psychosocial stress exposures in US dental schools: the need for expanded ergonomics training. Applied Ergonomics;35(2):153-157.

[12] Americal American Dental Association INFOpak. (2008).Ergonomics for Dental Students. ADA INFOpak:1-4.

[13] Valachi B. (2010). Ergonomic Positioning: A Few Degrees Add Years to Your Career. Acedido em: http://www.dentistrytoday.com/ergonomics/3481-ergonomic-positioning-a-few-degreesadd-years-to-your-career

[14] Gupta S. (2011). Ergonomic applications to dental practice. Indian J Dent Res.;22(6):816-22.

[15] Bramson JB., Smith S, Romagnoli G. 1998. Evaluating Dental Office Ergonomic Risk Factors And Hazards. J Am Dent Assoc;129:174-183

[16] Szymanska J. (2002). Disorders of the Musculoskeletal System among Dentists from the Aspect of Ergonomics and Prophylaxis. Ann Agric Environ Med;9:169-173.

[17] Valachi B, Valachi K. (2003a).Mechanisms leading to musculoskeletal disorders in dentistry. J Am Dent Assoc;134:1344-1350

[18] Valachi B. (2009). Magnification in Dentistry: How Ergonomic Features Impact Your Health. Acedido em: http://www.dentistrytoday.com/ergonomics/1110

[19] Nutalapati R, Gaddipati R, Chitta H, Pinninti M, Boyapati R. (2009). Ergonomics in Dentistry and the Prevention of Musculoskeletal Disorders in Dentists. The Internet Journal of Occupational Health. Vol 1;1.

[20] The Hartford Financial Services Group, Inc. (2009). Ergonomic Risks in Dentistry. The Hartford (3):1-4.

[21] Creasy JE, Mines P, Sweet M. (2009). Surgical trends among endodontists: the results of a webbased survey. J Endod;35:30. 
[22] Berguer R. (1999). Surgery and ergonomics. Arch Surg;134:1011.

[23] Buffington CW, MacMurdo SD, Ryan CM.(2006). Body position affects manual dexterity. Anesth Analg;102:1879

[24] Patkin's M. (1977). Ergonomics applied to the practice of microsurgery. Aust. N. Z. Jl Surg. 43/3:320-329. Acedido em: http://mpatkin.org/surg_micro/erg_opmicrosc.htm

[25] Carreira, L. Miguel. (2014). The Use of Microsurgery for the Excellence Performance in the modern Dental Medicine Specialties. Master Science Thesis, for graduation in Human Dental Medicine, Egas Moniz Health Sciences Institute - Caparica- Portugal

[26] Guay AH. (1998). Commentary: Ergonomically related disordes in dental practs. J Am Dent Assoc.;129(2):184-6

[27] Nutalapati R, Gaddipati R, Chitta H, Pinninti M, Boyapati R. (2009). Ergonomics in Dentistry and the Prevention of Musculoskeletal Disorders in Dentists. The Internet Journal of Occupational Health. Vol 1;1

[28] Castellucci A. (2003). Advances in surgical Endodontics. L'informatore Endodontico; Vol.6,1:115

[29] Lippold O.(1970). Physiological tremor. J Physiol,206:359-382

[30] Harwell RC, Ferguson RL. (1983). Physiological tremor and microsurgery. Microsurgery; 4(3):187-92

[31] Bye RT, Neilson PD. (2010).The BUMP model of response planning: Intermittent predictive control accounts for $10 \mathrm{~Hz}$ physiological tremor. Human Movement Science, 29, Issue 5:713-736

[32] Lakie M, Vernooij CA, Osborne TM, Reynolds RF. (2012). J Physiol, 590:2471-83

[33] Herbert R.(2012). Shaking when stirred: mechanisms of physiological tremor. J Physiol; 1, 590, (11) 2549

[34] Stephans JA, Tylor A. (1974). The effects of visual feedback on physiological muscle tremor. Clin Neurophysiol; 36:pp.456-464. In: Milton JG, Longtin A, Beuter A, Mackey MC, Glass L. (1989). Complex Dynamics and Bifurcations in Neurology. J. Theor. Biol, 138:129-147

[35] Glencross DJ, Whiting HTA, Abernethy B.(1994). Motor control, motor learning and the acquisition of skill: historical trends and future directions. Int J Sport Psychol, Rome, v. 25:32-52

[36] Carr GB. (1998). Magnification and illumination in endodontics. In: Hardin JF, ed. Clark's clinical dentistry. Vol. 4. New York: Mosby:1-14

[37] Alvarez N. (2013). Tremors. Accessed: http://www.emedicinehealth.com/tremors/article_em.htm

[38] Findley LJ. (1996). Classification of tremors. J Clin Neurophysiol. Mar;13(2):122-32

[39] Evidenty VG. 2000. Understanding essential tremor. Differential diagnosis and options for treatment. Postgrad Med. 108(5):138-40, 143-6, 149

[40] Crawford P, Zimmerman EE. (2011). Differentiation and diagnosis of tremor. Am Fam Physician.15; 83(6):697-702

[41] Gonzalez-Usigli H, Espay A. (2013). Tremor: A Merck Manual of Patient Symptoms podcast

[42] Glencross DJ. (1980). Levels and strategies of response organization. In: Stelmach,GE, Requin J. Tutorials in motor behaviour. Amestredam, Cap 34:551-556

[43] Glencross DJ, Whiting HTA, Abernethy B.(1994). Motor control, motor learning and the acquisition of skill: historical trends and future directions. Int J Sport Psychol, Rome,V25:32-52

[44] Alleoni BN, Pellegrini AM.(2006). Desempenho espacial e temporal de tarefas bimanuais em função da atenção e da preferência manual. III Congresso Brasileiro de Comportamento Motor, ANAIS, São Paulo

[45] Puente CG, Saavedra JJ. (2005). Microcirurgia en endodoncia. Cap.35;pp:1450-91;In:Leonardo MR, Leonardo RT.2005. Tratamiento de los Conductos Radiculares. Principios técnicos e biológicos. Vol2, São Paulo, Brasil

[46] Merino EM. (2009b).Endodontic Microsurgery. Quintessence Pub Co; 1 Ed:26-28

[47] Shanelec,DA(2003).Periodontal Microsurgery. J Esthet and Restor Dent,15:402-407

[48] Niemczyk SP. (2010). Essentials of endodontic microsurgery. Dent Clin North Am;54(2):375-99 
The importance of Ergonomics for Dental Medicine Procedures in the Triad Position: The Patient, the Dentist, and the Surgical Microscope

[49] Gorduysus MO, Gorduysus M, Friedman S.(2001). Operating microscope improves negotiation of second mesiobuccal canals in maxillary molars J Endod 27:683-6

[50] Comes C, Valceanu A, Rusu D. (2008). A study on the ergonomical working modalities using the dental operating microscope (DOM). Part 1: ergonomic principles in dental medicine. TMJ;58(3-4):218

[51] Michaelides PL. (1996). Connective-tissue root coverage using microsurgery. Dent Today.;15(10):74:76-9

[52] Sheets, CG, Paquette JM. (1998). Enhancing Precision Through Magnification. Dentistry Today. $17 ; 1: 44-49$

[53] Hokwerda O, Wouters JAJ, de Ruijter RAG \& Zijlstra-Shaw, S. (2007).Ergonomic requirements for dental equipment. Guidelines and recommendations for designing, constructing and selecting dental equipment. Acedido em: www.optergo.com/images/Ergonomic_req_april2007.pdf

[54] Grandjean E. (1998). Manual de ergonomia: adaptando o trabalho ao homem. Tradução: João Pedro Stein. Porto Alegre: Bookman, 310

[55] Friedman M, Mora AF, Schmidt R. (1999). Microscope-assisted precision dentistry. Compend Contin Educ Dent; 20(8):723-8

[56] Comes C, Valceanu A, Rusu D. (2008). A study on the ergonomical working modalities using the dental operating microscope (DOM). Part 1: ergonomic principles in dental medicine. TMJ;58(3-4):218

[57] Rubinstein RA. (1997). Endodontic Microsurgery and the Surgical Operating Microscope. Compendium. 18; 7:659-672

[58] Valachi B, Valachi K. (2003a).Mechanisms leading to musculoskeletal disorders in dentistry. J Am Dent Assoc;134:1344-1350

[59] The Hartford Financial Services Group, Inc. (2009). Ergonomic Risks in Dentistry. The Hartford (3):1-4 